
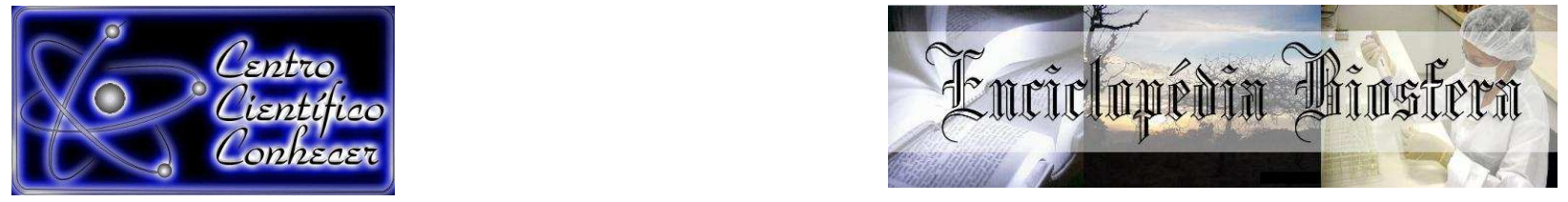

\title{
SISTEMA REPRODUTIVO E POTENCIAL DE HIBRIDAÇÃO ENTRE ESPÉCIES SIMPATRICAS DE Senna (FABACEAE) EM AMBIENTE DE CERRADO
}

\author{
Tamara Poliana de Oliveira Teixeira ${ }^{1}$, Cristiana Barros Nascimento Costa ${ }^{2}$, \\ Ana Maria Mapeli ${ }^{3}$ \\ 1 Mestranda em Biodiversidade Vegetal da Universidade Federal do Goiás. \\ Goiânia - Brasil. (marahadassa@hotmail.com) \\ 2 Docente da Universidade Federal do Sul da Bahia \\ 3 Docente da Universidade Federal do Oeste da Bahia
}

Recebido em: 03/10/2016 - Aprovado em: 21/11/2016 - Publicado em: 05/12/2016 DOI: 10.18677/EnciBio_2016B_089

\begin{abstract}
RESUMO
As espécies Senna obtusifolia e Senna occidentalis ocorrem simpatricamente em ambiente de Cerrado, no município de Barreiras, Bahia. Polinizações experimentais foram realizadas para verificar o sistema reprodutivo de cada espécie e determinar se há 0 isolamento reprodutivo entre elas. Ambas as espécies apresentam flores amarelas, diclamídeas, pentâmeras, dialissépalas, dialipétalas, os estames são heteromorfos e as anteras possuem deiscência poricida, necessitando de abelhas especializadas que vibrem para a liberação do pólen. A semelhança da biologia floral permite que estas tenham a mesma guilda de polinizadores, Trigona spinipes, Bombus sp, Xylocopa frontalis, e Centris sp. O índice de autoincompatibilidade foi calculado, indicando que $S$. obtusifolia e $S$. occidentalis são autocompatíveis, sendo autogâmicas. A polinizações interespecíficas indicam a intercompatibilidade entre os dois táxons, evidenciando que não existe isolamento reprodutivo prézigótico, porém a baixa potencialidade de germinação das suas sementes pode reduzir o potencial de hibridação.
\end{abstract}

PALAVRAS- CHAVE: Biologia Reprodutiva; hibridação; Isolamento reprodutivo

\section{REPRODUCTIVE AND HYBRIDIZATION BETWEEN POTENTIAL OF SPECIES SYMPATRIC Senna (FABACEAE) IN CERRADO}

\begin{abstract}
Senna obtusifolia and Senna occidentalis occur sympatrically in Cerrado at Barreiras, Bahia. Experimental pollinations were performed to verify the reproductive system of each species and determine whether there is reproductive isolation between them. Both species have yellow flowers, dichlamydeous, pentamerous, dialisepal, dialipetal, stamens and anthers are heteromorfos and they have poricida dehiscence, requiring specialized bees that vibrate to release pollen. The similarity of the floral biology between these species allows to them have the same guild of pollinators, Trigona spinipes, Bombus sp, Xylocopa frontalis, and Centris sp. The self-incompatibility index was calculated, indicating that $\mathrm{S}$. obtusifolia and $\mathrm{S}$. occidentalis are self-incompatible, being autogamous and self-spontaneous. The interspecific pollinations indicate there is compatibility between the two taxa, showing that there are not reproductive
\end{abstract}


isolation, however a low potentiality of seeds germination can reduce the potential for hybridization.

KEYWORDS: Reproductive Biology; Hybridization; Reproductive isolation

\section{INTRODUÇÃO}

O gênero Senna pertence à família Fabaceae e apresenta distribuição pantropical com cerca de 350 espécies, sendo que cerca de 200 destas ocorrem na América (BEGUN et al., 2014). No Brasil está representado por aproximadamente 81 espécies, na qual 33 são endêmicas (BGF, 2015). Inclui espécies com enantiostilia, flores assimétricas e espécies com nectários extraflorais (IRWIN \& BARNEBY, 1982).

As espécies Senna occidentalis (L.) H.S Irwin \& Barneby e Senna obtusifolia (L.) Link pertencem as seções distintas dentro do gênero e são consideradas espontâneas no Cerrado, podem ser tóxicas para alguns animais (TAKEUTI et al., 2011), possuem potencial medicinal (SILVA et al., 2015) e estão entre espécies chaves para a conservação de algumas abelhas do gênero Xylocopa (MAIA - SILVA et al., 2012).

Apesar de sua referida importância, poucos trabalhos com enfoque no sistema reprodutivo foram realizados para o gênero no Brasil (CARVALHO \& OLIVEIRA, 2003; WOLOWSKI \& FREITAS, 2010; SOUZA et al., 2012) E ainda não existem trabalhos abordando o isolamento reprodutivo entre essas espécies.

Com o conhecimento do sistema reprodutivo é possível entender a complexidade taxonômica e os padrões do fluxo gênico, sendo importante para estudos da evolução e genética de populações (RICHARDS, 1997). Tal informação é fundamental para o esclarecimento do processo de especiação e das relações genéticas entre as espécies (MESQUITA - NETO et al., 2015).

As espécies $S$. obtusifolia e $S$. occidentalis ocorrem simpatricamente no Cerrado baiano e esta condição dá possibilidade de se formar híbridos devido ao fluxo gênico promovido por intercruzamentos (COSTA et al., 2007). Porém este potencial pode ser limitado por mecanismos pré-zigóticos e pós-zigóticos que atuam como barreiras reprodutivas entre os táxons (FERRER \& GOOD, 2012).

Conhecimento sobre fenologia, ecologia da polinização, formação de sementes e técnicas de reprodução são instrumentos indispensáveis para caracterizar o sistema reprodutivo das espécies e diversas estratégias são encontradas entre as plantas possibilitando certo controle da estrutura genética de suas populações e o padrão de sua evolução (PAPADOPULUS et al., 2011). Assim, esse trabalho objetiva contribuir com elucidação da biologia reprodutiva e mecanismos de isolamento reprodutivo em Senna obtusifolia e Senna occidentalis, em ambiente do Cerrado baiano.

\section{Área de estudo}

\section{MATERIAL E MÉTODOS}

O trabalho foi desenvolvido no Campus Reitor Edgard Santos - Prainha da Universidade Federal do Oeste da Bahia (UFOB), que se encontra nas coordenadas $11^{\circ} 37^{\prime} \mathrm{e} 12^{\circ} 25^{\prime} \mathrm{S}$ e $44^{\circ} 34^{\prime}$ e $46^{\circ} 23^{\prime} \mathrm{W}$, altitude média de $457 \mathrm{~m}$, localizado no município de Barreiras, oeste da Bahia. O principal tipo de vegetação na região é o Cerrado, predominando floresta estacional na área de trabalho. As espécies estudadas estão distribuídas em uma área antropizada, predominando principalmente nas bordas da vegetação. 
O clima do município de Barreiras, conforme a classificação de Koppen é do tipo Aw, com o inverso seco e temperatura média do ar do mês mais frio superior a $20{ }^{\circ} \mathrm{C}$ (SOARES - NETO et al., 2013).

\section{Biologia floral}

Para cada espécie estudada foi analisado o tipo de inflorescência, localização e número de flores por inflorescência dos indivíduos por meio de contagem direta. Os verticilos foram medidos com papel milimetrado. Foi acompanhado o horário de antese a partir de observações diretas para visualizar o momento em que as flores se abrem. A duração das flores foi observada desde sua abertura até o processo de senescência. A disponibilidade do pólen foi verificada mediante o toque manual nas anteras, apesar destas serem poricidas os grãos de pólens são liberados facilmente quando é removido um revestimento que se encontra no ápice dos poros.

A receptividade estigmática foi determinada em campo através da observação do estigma com lupa de mão (10x), utilizando-se peróxido de hidrogênio, segundo o método descrito por DAFNI (2005). As flores levadas para exame em laboratório foram acondicionadas em frascos com álcool $70 \%$. Para as medidas florais foram usadas 20 flores de 20 indivíduos diferentes para análise de cada estrutura.

Verificou-se a viabilidade polínica com o uso do carmim acético (SILVA NETO et al., 2013), analisando 10 lâminas para grãos de pólen provindos dos estames maiores, estames menores e estaminódios separadamente. A presença de pigmentos ultravioleta foi testada com uso de vapor de hidróxido de amônia e a presença de osmóforos detectada como o uso de vermelho neutro (DAFNI, 2005).

\section{Visitantes florais}

Os visitantes florais foram observados desde as cinco horas da manhã até ás $17 \mathrm{~h}$. As observações foram realizadas principalmente durante o pico de floração de cada táxon. O tempo de observação para cada espécie totalizou 40hs distribuídas ao longo do dia: comportamento de forrageio, a coleta de recurso floral, o local de contato com o estigma e a frequência das visitas foram verificados. Os exemplares dos visitantes foram coletados com rede entomológica e identificados quando possível ao menor nível taxonômico.

\section{Sistema Reprodutivo e Potencial de hibridação}

O sistema reprodutivo foi verificado em campo a partir de polinização experimental manual para cada espécie: autopolinização manual e espontânea, polinização cruzada intraespecífica e interespecífica. Para realizar os experimentos, foram utilizadas flores no dia de antese, que haviam sido ensacadas previamente em fase de botão, e novamente ensacadas após a realização da polinização. Os tratamentos foram feitos pela manhã, horário em que as flores já estavam abertas, o pólen disponível e o estigma receptivo.

Foram marcadas 155 flores para $S$. occidentalis e 45 para $S$. obtusifolia com fitas coloridas, sendo estes os grupos controles, para observação das frutificações ao natural. Para verificar a ocorrência de autopolinização espontânea, ensacou-se 72 botões florais de $S$. occidentalis e 42 de $S$. obtusifolia, sem nenhum tipo de tratamento. $\mathrm{Na}$ autopolinização manual foram usadas flores do mesmo indivíduo, e para a polinização cruzada, foi usado pólen de diferentes indivíduos com pelo menos $15 \mathrm{~m}$ de distância. As polinizações foram realizadas utilizando-se alfinetes para 0 processo de transferência do grão de pólen para o estigma das flores e para a realização das polinizações cruzadas, foi utilizado pólen de 2-3 flores de indivíduos 
diferentes. Para determinar se as espécies apresentavam mecanismos de isolamento reprodutivo, foram feitas polinizações interespecíficas bidirecionais, com ambos os táxons testados como receptores e doadores de pólen.

O Índice de autoincompatibilidade foi calculado dividindo o percentual de frutificações provenientes de autopolinizações pelo percentual de frutificações oriundas de polinizações cruzadas, sendo que valores acima de 0,8 indica que a espécie é autoincompatível (RADUSKI et al., 2011).

Algumas flores advindas dos tratamentos foram fixadas em FAA (formalina, ácido acético e álcool etílico) a $50 \%$, por $24 \mathrm{~h}$, e transferidas para álcool $70 \%$. Posteriormente, foram tratadas com hipoclorito de sódio lavadas com água destilada e coradas com azul de anilina, para observação em microscópio de epifluorescência (GANDOLPHI \& BITTENCOURT JÚNIOR, 2010), para observação do crescimento do tubo polínico e fertilização dos óvulos.

\section{Germinação das sementes}

Os frutos desenvolvidos a partir dos experimentos de polinização manual foram acompanhados desde a sua formação até o amadurecimento. As sementes foram removidas manualmente e submetidas a um processo de seleção de acordo com tamanho e ausência de dano. Em seguida desinfestadas com hipoclorito de sódio a $2 \%$ e lavadas com água destilada. Foram selecionadas 20 sementes para cada repetição, ou o total de sementes formadas nos experimentos.

Posteriormente foram colocadas em placa de petri com papel filtro e aproximadamente $2 \mathrm{~mL}$ de água, acondicionadas em temperatura ambiente e fotoperíodo constante e logo após avaliadas pelo o potencial germinativo diariamente (GUIMARÃES et al 2015). A germinação foi avaliada diariamente, considerando a protrusão radicular $(2 \mathrm{~mm})$. O índice de velocidade de germinação (IVG) foi determinado a partir das quatro repetições, usando a Equação 1 proposta por MAGUIRE (1962):

$\mathrm{IVE}=\mathrm{E} 1 / \mathrm{N} 1+\mathrm{E} 2 / \mathrm{N} 2+\ldots \mathrm{En} / \mathrm{Nn}$

Em que:

IVE = índice de velocidade de emergência.

$\mathrm{E} 1, \mathrm{E} 2, \ldots \mathrm{En}$ = número de plântulas normais computadas na primeira contagem, na segunda contagem e na última contagem.

$\mathrm{N} 1, \mathrm{~N} 2, \ldots \mathrm{Nn}$ = número de dias da semeadura à primeira, segunda e última contagem.

O experimento foi montado em delineamento inteiramente casualizado (DIC), sendo a unidade experimental composta de quatro seleções, referente as quatro repetições, os dados foram submetidos á análise de variância e as médias comparadas ao teste Scott-Knott 95\% de significância estatística.

\section{Biologia Floral}

\section{RESULTADOS E DISCUSSÃO}

As espécies $S$. obtusifolia e $S$. occidentalis têm morfologia floral semelhantes, ambas são amarelas, zigomorfas e apresentam heteranteria. Possuem pequenas variações no diâmetro dos verticilos e diferem no número de flores expostas por dia. Em S. obtusifolia as inflorescências são do tipo paniculada, em cada inflorescência abrem-se, no máximo, duas flores por dia, as quais têm em média, $1,5 \mathrm{~cm}$, são diclamídeas, dialipétalas $( \pm 0,9 \mathrm{~cm})$, dialissépalas $( \pm 0,5 \mathrm{~cm})$, pentâmeras e zigomorfas. $O$ androceu é constituído por 3 estames maiores $( \pm 0,8 \mathrm{~cm}), 4$ estames 
menores $( \pm 0,4 \mathrm{~cm})$ e 2 estaminódios $( \pm 0,2 \mathrm{~cm})$. As anteras apresentam deiscência poricida, sendo bastante degradadas por abelhas. $\mathrm{O}$ pólen encontra-se disponível desde às 7 horas da manhã.

O gineceu $( \pm 1,2 \mathrm{~cm})$ é alongado, de coloração verde, ovário súpero e unilocular, com placentação parietal. O estigma possui ápice circular e sua abertura está voltada para a parte interna da flor. Encontra-se receptivo a partir das 7 horas. A média da viabilidade polínica em S. obtusifolia para os estames maiores foi de $97,6 \%$, os estames menores $96,1 \%$ e nos estaminódios não foram encontrados grãos de pólen viáveis. A partir das 6 horas da manhã as flores já se encontravam em antese e duram apenas um dia, se fechando no final da tarde. Cerca de 48 horas após polinização, os estames e pétalas começam a cair.

As anteras reagiram ao vermelho neutro e o estigma ao peroxido de hidrogênio, sendo a presença de osmóforo verificada da base ao ápice da antera (Figura 1). Em S. obtusifolia foi observado ocorrência de enantiostilia do tipo monomórfica, em que no mesmo indivíduo pode ser encontrada flores com o gineceu voltado para a direita e outros voltados para a esquerda em relação ao centro floral, característica comum para o gênero (FERRER et al., 2011). A espécie $S$. occidentalis possui inflorescência do tipo paniculada e em cada inflorescência abrem-se, no máximo, quatro flores por dia, as flores têm em média $1,5 \mathrm{~cm}$, são de coloração amarelas, diclamídeas, dialipétalas $( \pm 1,2 \mathrm{~cm})$, dialissépalas $( \pm 0,8 \mathrm{~cm})$, pentâmeras e zigomorfas. $O$ androceu é constituído por 2 estames maiores $( \pm 1,0$ $\mathrm{cm}), 4$ estames menores $( \pm 0,7 \mathrm{~cm})$ e 3 estaminódios $( \pm 04 \mathrm{~cm})$. As anteras são de deiscência poricida, o pólen encontra-se disponível desde às 9 horas.

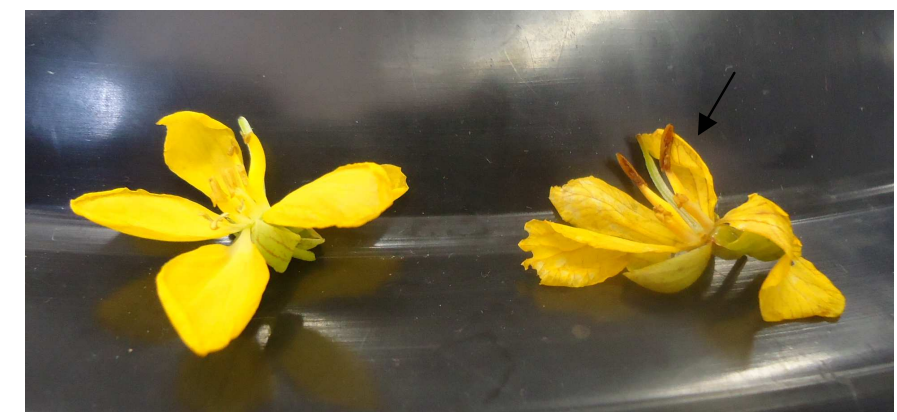

FIGURA 1: Presença de osmóforos detectados no apíce da antera de Senna occidentalis após o uso de vermelho neutro; flor do lado esquerdo sem o teste, flor do lado direito após o reagente.

O gineceu $( \pm 1,3 \mathrm{~cm})$ é alongado, ovário súpero e unilocular, com placentação parietal. O estigma possui pigmentação vináceas e ápice achatado com presença de tricomas bem visíveis. Sua abertura está voltada para a parte interna da flor, encontra-se receptivo desde ás 7 horas. Os estames maiores apresentaram média de viabilidade polínica de $92,2 \%$, os estames menores $92 \%$ e os estaminódios não apresenta pólen viável. A antese ocorre por volta das $6 \mathrm{~h}$ e duram apenas um dia, fechando no final da tarde. Após 48 horas de polinização os estames e pétalas começaram a cair. As anteras reagiram ao vermelho neutro, sendo a presença de osmóforos verificada da base ao ápice da antera. Em S. occidentalis o estigma apresenta ápice plumoso direcionado para as anteras maiores.

S. obtusifolia e S. occidentalis apresentam aspecto da morfologia floral semelhante aos de outras espécies da subtribo Cassiinae com pistilo curvo direcionado aos estames (Figura 2) e a presença de heteranteria (GOTTSBERGER 
\& GOTTSBERGER, 1988; WOLOWSKI \& FREITAS, 2010), o que pode favorecer a utilização do pólen para a alimentação e para a polinização. Algumas espécies de abelhas utilizam os estames menores como ponto de fixação durante as visitas (GOTTSBERGER \& GOTTSBERGER, 1988; CARVALHO \& OLIVEIRA, 2003).

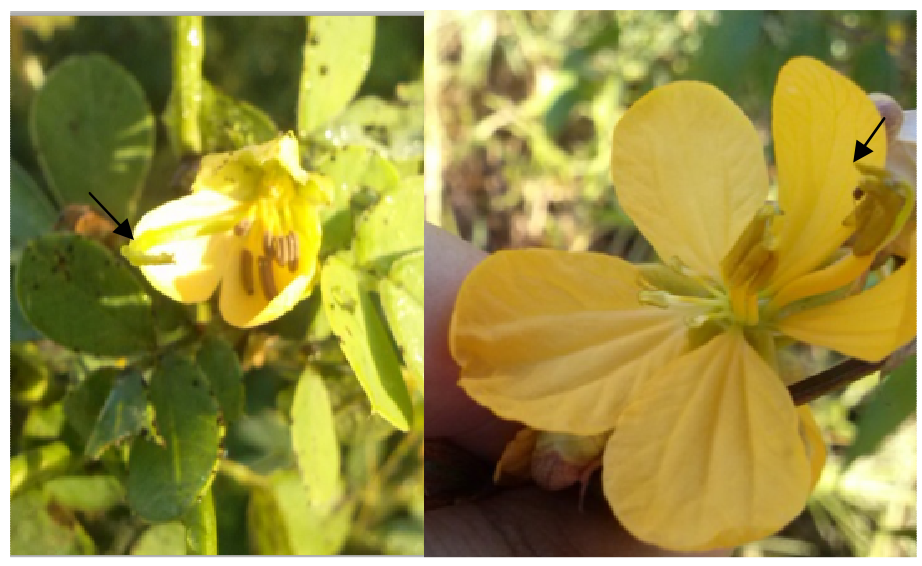

FIGURA 2: Lado esquerdo Senna obtusifolia; lado direito S. occidentalis; Pistilos curvos em direção aos estames (seta).

Com exceção dos estaminódios, os testes de viabilidade polínica indicaram que tanto os grãos de pólen dos estames maiores, quanto os menores das espécies estudadas são férteis, podendo ser utilizados para alimentação e também para a fertilização. Os dados são semelhantes aos encontrados nos trabalhos de CARVALHO \& OLIVEIRA (2003) e WOLOWSKY \& FREITAS (2010), para as espécies de Senna sylvestris e Senna multijuga, respectivamente.

A heteranteria observada em algumas espécies, podem atuar como uma estratégia eficaz na economia de pólen utilizado no serviço de polinização (FERREIRA \& ARAUJO, 2016) como também as diferenças de orientação dos poros das anteras, provavelmente evidenciam uma evolução em relação à polinização por vibração. Estas características influenciam a liberação do pólen e a assimetria da corola, desempenhando papel relevante durante 0 processo de polinização (MARAZZI et al., 2007).

Estudos recentes sugerem que quanto maior a frequência dessas vibrações durante a visita, maior a taxa de fertilização, isso porque, quando as anteras vibram para a liberação do pólen, também ocorre a captura do pólen e deposição no estigma (ARCEO-GOMEZ et al., 2011).

Em espécies dos gêneros Senna já foi registrada a predominância de enantiostilia (IRWIN \& BARNEBY, 1982; SOUZA et al., 2012). Segundo WOLOWSKI \& FREITAS (2010) flores assimétricas, enantiostilicas, com heteranteria e deiscência poricida são características típicas do gênero Senna. Nas espécies objeto desse estudo apenas em $S$. obtusifolia foi verificado enantiostilia, tal característica favorece o aumento de polinizações cruzadas e geralmente está associada com a polinização por vibração (ALMEIDA et al., 2012).

As flores de Senna geralmente possuem cores bastante evidentes, atraindo abelhas coletoras exclusivas de pólen que também são polinizadoras de outras flores de Cassinae (GOTTSBERGER \& GOTTSBERGER, 1988). Este mecanismo aumenta o fluxo gênico entre as espécies. Desse modo, como $S$. obtusifolia e $S$. occidentalis apresentam o mesmo padrão de morfologia floral acabam sobrepondo semelhantes polinizadores (RECH et al., 2014). 


\section{Visitantes florais}

Durante a observação focal ao longo da floração, as flores de $S$. obtusifolia e S. occidentalis foram visitadas por diversos insetos, distribuídos entre Díptera e Hymenoptera (Tabela 1). Quanto ao comportamento dos insetos na flor, as visitas em geral iniciavam-se por volta das $6 \mathrm{~h}$, coincidindo com o período de maior atividade. A partir das $07 \mathrm{~h} 30 \mathrm{~min}$ as visitas começavam a diminuir. De maneira geral, as visitas duraram até três segundos, vale destacar que as abelhas visitaram diversas flores numa mesma inflorescência.

TABELA 1. Visitantes florais de Senna obtusifolia e Senna Occidentalis em ambiente de cerrado.

\begin{tabular}{|c|c|c|c|c|}
\hline Ordem/ Família & Espécie & S.obtusifolia & S. occidentalis & $\begin{array}{c}\text { Total de } \\
\text { visitas }\end{array}$ \\
\hline \multirow{4}{*}{$\begin{array}{l}\text { HYMENOPTERA } \\
\text { Apidae }\end{array}$} & Trigona sp & $2(4,65 \%)$ & $18(28,12 \%)$ & 20 \\
\hline & Bombus sp & $15(34,80 \%)$ & $17(26,56 \%)$ & 32 \\
\hline & $\begin{array}{l}\text { Xylocopa } \\
\text { frontalis }\end{array}$ & $18(41,86 \%)$ & $5(7,81 \%)$ & 23 \\
\hline & Centris sp & $2(4,65 \%)$ & $22(34,37 \%)$ & 24 \\
\hline $\begin{array}{l}\text { HYMENOPTERA } \\
\text { Vespidae }\end{array}$ & $\begin{array}{c}\text { Não } \\
\text { identificada }\end{array}$ & $2(4,65 \%)$ & - & 2 \\
\hline $\begin{array}{l}\text { HYMENOPTERA } \\
\text { Formicidae }\end{array}$ & $\begin{array}{c}\text { Não } \\
\text { identificada } \\
\text { Não }\end{array}$ & $2(4,65 \%)$ & $2(3,125 \%)$ & 4 \\
\hline DIPTERA & identificada & $2(4,65 \%)$ & - & 2 \\
\hline
\end{tabular}

A maior atividade das abelhas coincidiu com a ocasião em que as anteras já se encontravam com os poros abertos e com pólen disponível. A maioria dos visitantes pertence à família Apidae, sendo que Trigona spinipes foi observada em ambos os táxons, mas com maior frequência em $S$. occidentalis, apresentando comportamento pilhador cortando as anteras para coletar pólen.

Todos os táxons tiveram como polinizadores espécies de abelhas que realizavam processo de vibração das anteras para coleta de pólen. As espécies estudadas apresentaram sobreposição de visitantes florais. A espécie Xylocopa frontalis foi observado com grande frequência em S. obtusifolia $(41,86 \%)$ e Centris sp em Senna occidentalis (34,37\%). Houve maior sobreposição de visitantes florais da espécie Bombus sp para as duas espécies, correspondendo $34,80 \%$ das visitas em S. obtusifolia e $26,56 \%$ em S. occidentalis.

Entre as abelhas o comportamento foi semelhante, todas elas aproximavam da flor, pousavam nas pétalas, agarravam as anteras e vibravam para a liberação do pólen. O tempo das visitas relacionou-se à disposição da oferta de pólen pelas flores. Os outros insetos observados (formigas, vespas, moscas e outros) tiveram uma menor frequência, aparecendo esporadicamente. Estes não foram considerados polinizadores, já que não tocavam no estigma, é importante ressaltar que pelo fato das anteras de $S$. obtusifolia e $S$. occidentalis serem poricidas necessita de um polinizador capaz de vibrar as anteras para a liberação do pólen.

As abelhas do gênero Xylocopa, Bombus, e Centris observadas nas duas espécies estudadas são consideradas polinizadores de sucesso, vibram os estames 
centrais durante suas visitas e recebem o pólen no lado ventral de seus corpos, no lado interior de suas pernas e em suas peças bucais (SILVA-NETO et al. 2013).

A alta frequência de $X$. frontalis em S.obtusifolia sustenta a ideia em que para se manter a população dessas abelhas no cerrado é necessário também a conservação de S. obtusifolia (MAIA - SILVA et al., 2012). As abelhas $X$. frontalis, Centris sp e Bombus sp possuem padrão de visitas semelhantes. Estas chegam e saem das plantas na mesma direção, sugerindo a manutenção de rotas de forrageamento "traplining". Tal comportamento favorece o fluxo polínico e consequentemente a polinização cruzada (CARVALHO \& OLIVEIRA, 2003).

Os polinizadores de $S$. obtusifolia e $S$. occidentalis na área de estudo pertencem aos mesmos gêneros (Xylocopa, Centris, Bombus) dos polinizadores de outras espécies de Senna (GOTTSBERGER \& GOTTSBERGER, 1988; CARVALHO \& OLIVEIRA, 2003; LAPORTA, 2005; WOLOWSKI \& FREITAS, 2010; SOUZA et al., 2012).

\section{Sistema reprodutivo e Potencial de hibridação}

Nas Tabelas 2 e 3 são apresentados os resultados dos diferentes tratamentos realizados para $S$. occidentalis e $S$. obtusifolia, respectivamente. $S$. occidentalis desenvolveu frutos e sementes em todos os tratamentos, com maior sucesso de produção de frutos na autopolinização manual. Houve formação de frutos por autopolinização espontânea, o que não é comum, já que as flores possuem anteras poricidas e necessita de um polinizador que vibrem as suas anteras. Neste caso deve ser explicado que não foi feito teste de apomixia ou agamospermia para verificar se a formação de frutos ocorre com presença ou ausência de pólen (agamospermia)

TABELA 2- Produção de frutos (porcentagem do número de frutos/número de flores) após tratamento de polinização controlada de Senna occidentalis em área de cerrado Barreiras-Bahia.

\begin{tabular}{ccc}
\hline Tratamentos & $\mathrm{N}^{\circ}$ de flores & $\mathrm{N}^{\circ}$ de frutos $(\%)$ \\
\hline Autopolinização & 72 & $26(36,1)$ \\
espontânea & & \\
Autopolinização manual & 32 & $25(78,1)$ \\
Grupo controle & 155 & $33(21,3)$ \\
Polinização cruzada & 30 & $21(70)$ \\
\hline
\end{tabular}

TABELA 3- Produção de frutos (porcentagem do número de frutos/número de flores) após tratamento de polinização controlada de Senna obtusifolia em área de cerrado Barreiras-Bahia.

\begin{tabular}{ccc}
\hline Tratamentos & $\mathrm{N}^{\circ}$ de flores & $\mathrm{N}^{\circ}$ de frutos $(\%)$ \\
\hline Autopolinização & 42 & $3(7,14)$ \\
espontânea & & \\
Autopolinização manual & 30 & $4(13,1)$ \\
Grupo controle & 45 & $38(84,4)$ \\
Polinização cruzada & 30 & $20(66,6)$ \\
\hline
\end{tabular}

Os índices de autoincompatibilidade (ISI) foram de - 0,1 para autopolinização manual e 0,5 para autopolinização espontânea, constatando-se que Senna occidentalis é auto compatível. Para S. obtusifolia o tratamento que produziu maior quantidade de frutos foi o do grupo controle, o ISI foi de 0,10 para autopolinização 
espontânea e 0,19 para autopolinização manual, indicando que esta também é autocompatível.

Nos experimentos de polinizações cruzadas interespecíficas, as espécies se mostraram autocompatíveis, tanto como doadoras, como receptoras de pólen (Tabela 4), não sendo evidenciado isolamento reprodutivo pré-zigótico. A maior formação de frutos ocorreu no experimento em que $S$. obtusifolia foi doadora de pólen. Observou-se, por meio de microscopia de fluorescência, o crescimento do tubo polínico após 24 horas de $S$. occidentalis como receptora de pólen.

TABELA 4- Produção de frutos (porcentagem do número de frutos/número de flores) após tratamento de polinização cruzada interespecífica entre Senna obtusifolia e Senna Occidentalis em área de cerrado Barreiras - Bahia.

\begin{tabular}{ccccc}
\hline Tratamentos & $\begin{array}{c}\text { Doadora de } \\
\text { Pólen }\end{array}$ & $\begin{array}{c}\text { Receptora de } \\
\text { Pólen }\end{array}$ & $\begin{array}{c}N^{\circ} \text { de } \\
\text { Flores } \\
(\%)\end{array}$ & № de Frutos \\
\hline $\begin{array}{c}\text { Polinização } \\
\text { cruzada }\end{array}$ & $\begin{array}{c}\text { Senna } \\
\text { occidentalis }\end{array}$ & $\begin{array}{c}\text { Senna } \\
\text { obtusifolia }\end{array}$ & 30 & $8(26,6 \%)$ \\
$\begin{array}{c}\text { interespecífica } \\
\text { Polinização } \\
\text { cruzada }\end{array}$ & $\begin{array}{c}\text { Senna } \\
\text { obtusifolia }\end{array}$ & $\begin{array}{c}\text { Senna } \\
\text { occidentalis }\end{array}$ & 30 & $15(50 \%)$ \\
interespecífica & & & & \\
\hline
\end{tabular}

Em S. occidentalis houve uma diferenciação na morfologia externa dos frutos resultantes dos experimentos. Os frutos coletados em campo (controle) apresentam tamanhos maiores $( \pm 10,6 \mathrm{~cm})$ e são mais eretos. Frutos resultantes de autopolinização espontânea são curvos e de tamanho menor $( \pm 7,6 \mathrm{~cm})$. Os formados a partir de polinização manual são mais robustos e seu tamanho $( \pm 5,75$ $\mathrm{cm}$ ) é bastante reduzido. Frutos resultantes do cruzamento interespecífico também foram coletados, os quais apresentaram variedades de formas, sendo alguns alongados e outros mais curtos e robustos $( \pm 5,2 \mathrm{~cm})$.

Em todos os trabalhos de biologia reprodutiva de Senna o maior sucesso foi nas polinizações cruzadas (CARVALHO \& OLIVEIRA, 2003; LAPORTA, 2005; WOLOWSKI \& FREITAS, 2010; SOUZA et al., 2012) isso também foi verificado em $S$. obtusifolia, porém em $S$. occidentalis constatou-se maior sucesso reprodutivo em autopolinizações manuais. S. occidentalis e $S$. obtusifolia são autocompatíveis, estudos com biologia reprodutiva também mostraram autocompatibilidade para 0 gênero (LAPORTA, 2005; SOUZA et al., 2012)

Contudo $S$. occidentalis e $S$. obtusifolia além de autocompatível é autoespontânea, ou seja, é capaz de formar frutos sem a necessidade de um polinizador. Tal característica não é comum em espécies do gênero, já que estas apresentam anteras poricidas que necessitam de abelhas de grande porte que vibram para a liberação do pólen (GOTTSBERGER \& GOTTSBERGER, 1988). Esse aspecto pode estar relacionado ao seu comportamento invasivo, como pode ser uma estratégia evolutiva para se reproduzir sem a necessidade de vetores, já que estes têm reduzido suas populações principalmente pela ação antrópica (SILVA et al., 2012).

Os experimentos de cruzamento interespecífico constataram que não existe isolamento reprodutivo pré zigótico entre $S$. occidentalis e $S$. obtusifolia. Houve crescimento do tubo polínico após 24 horas do experimento (Figura 3), o que é 
possível, pois espécies que ocorrem em simpatria podem formar híbridos devido ao fluxo gênico promovido por intercruzamentos (COSTA et al. 2007; MESQUITANETO et al. 2015). A semelhança da morfologia floral, sobreposição de floração são mecanismos que facilitam esse processo. A diferença nos tamanhos dos frutos pode estar associada à variabilidade genética em que nas polinizações manuais e autoespontâneas é reduzida.

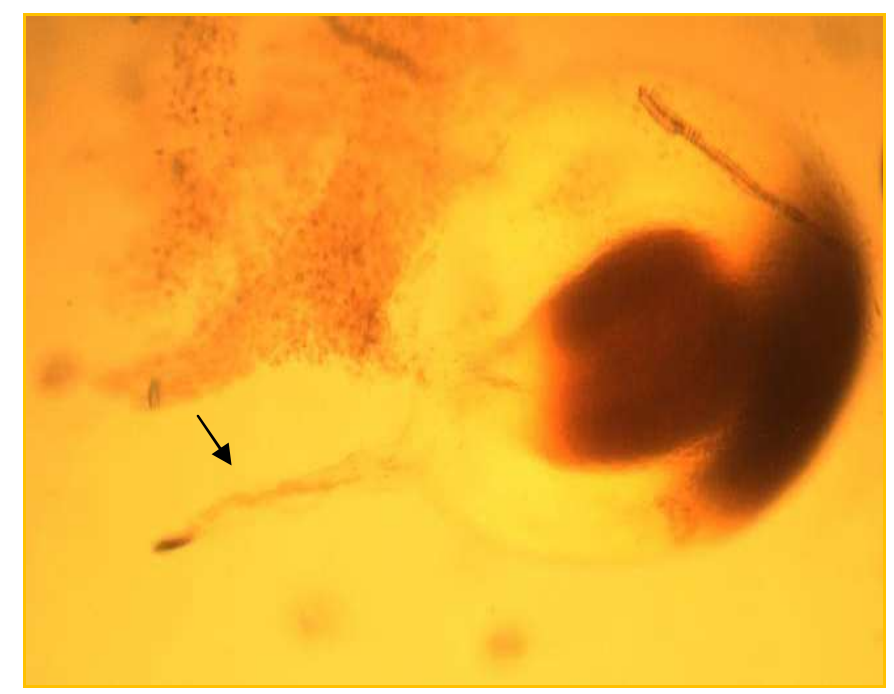

FIGURA 3: Crescimento do tubo polínico em que Senna occidentalis é receptora de pólen

Os resultados desse mesmo experimento, mostrou que existe uma diferença do percentual de frutificação, ou seja, quando $S$. obtusifolia foi receptora de pólen a taxa de frutificação foi inferior quando comparado com $S$. occidentalis como receptora. Como se trata de cruzamentos entre espécies de seções diferentes, pode ocorrer uma barreira reprodutiva por mecanismo pré- zigotico pós polinização com isolamento gamético, ou seja, os tubos polínicos alcançam o ovário, mas não penetram o tubo polínico na micrópila, esse tipo de barreira atua entre a polinização e fertilização, podendo desencadear a ausência de frutos ou a redução do número dos mesmos (COSTA et al. 2007).

\section{Potencial germinativo das sementes}

Somente as sementes do cruzamento interespecífico e dos tratamentos controle e espontânea de $S$. occidentalis foram testadas para a germinação, pois não havia frutos maduros dos outros experimentos. Após a germinação das sementes de $S$. occidentalis, verificou-se que o maior potencial germinativo, ocorreu no tratamento controle (Tabela 5). Apresentando também maior índice de velocidade de germinação (IVG).

Para o tratamento manual não foi possível organizar o experimento de acordo com a estatística, pois havia poucas sementes em cada repetição, entretanto estas germinaram $20 \%$. 
TABELA 5- Potencial germinativo e índice de velocidade de germinação de duas espécies de Senna em área de cerrado Barreiras - Bahia (IVG - Índice de velocidade de germinação).

\begin{tabular}{ccc}
\hline Tratamento & $\begin{array}{c}\text { Germinação } \\
(\%)\end{array}$ & IVG \\
\hline Controle & $68,3 \mathrm{a} \pm 4,59$ & $6,72 \mathrm{a} \pm 3,13$ \\
Espontânea & $23,7 \mathrm{~b} \pm 4,37$ & $0,35 \mathrm{a} \pm 0,05$ \\
$\begin{array}{c}\text { Cruzamento } \\
\text { interespecífico }\end{array}$ & $13,7 \mathrm{~b} \pm 1,87$ & $0,17 \mathrm{a} \pm 0,018$ \\
\hline
\end{tabular}

Um dos parâmetros mais utilizados para determinar o vigor de sementes é a velocidade de desenvolvimento que pode ser obtida a partir do índice de velocidade de germinação, logo sementes mais vigorosas germinarão mais rapidamente (GUIMARÃES et al., 2015).

Conforme apresentado na Tabela 5, o índice de velocidade de germinação foi maior para o grupo controle, o fato de o potencial germinativo ser baixo nas sementes provenientes do cruzamento interespecífico pode reduzir o potencial de hibridação, sendo portanto, uma barreira reprodutiva pós-zigótica (COSTA et al., 2007). Os resultados mostram que todas as sementes são viáveis, porém o maior sucesso de desenvolvimento são a do grupo controle.

A potencialidade de formação de frutos e sementes por autopolinização e polinização cruzada permite aos táxons de Senna estudados uma estratégia mista de reprodução sexuada. As angiospermas possuem diversas estratégias reprodutivas (BUSH \& URBAN, 2011) em que a autofertilização se faz uma estratégia importante, pois em circunstâncias em que a polinização cruzada é rara ou nula há possibilidade da espécie manter sua reprodução (RICHARDS, 1997).

No estudo de COSTA et al. (2007) o potencial germinativo para as espécies do gênero Chamaerista apresentaram maior valor aos tratamentos de autopolinização manual. As sementes advindas do cruzamento interespecífico apesar de não terem apresentado um alto IVG quando comparado aos outros tratamentos, mostra que existe possibilidade do desenvolvimento do híbrido.

\section{CONCLUSÕES}

O presente estudo revelou que Senna obtusifolia e Senna occidentalis são autocompatíveis e apresentam auto-espontâneadade. A biologia reprodutiva interespecífica evidencia que não há isolamento reprodutivo pré-zigótico entre $S$. obtusifolia e $S$. occidentalis, porém a baixa formação de frutos de $S$. obtusifolia como receptora de pólen pode estar relacionado a uma barreira reprodutiva por mecanismo pré- zigotico pós polinização com isolamento gamético. Concomitantemente o potencial germinativo das sementes provenientes do cruzamento das duas espécies reduz o sucesso na hibridação das mesmas, atuando como uma barreira reprodutiva pós-zigotica.

\section{REFERÊNCIAS}

ALMEIDA, N. M.; CASTRO, C. C.; LEITE, A. V. L.; NOVO, R. R.; MACHADO I. C. Enantiostyly in Chamaecrista ramos (Fabaceae Caesalpinioideae): floral 
morphology, pollen transfer dynamics and breeding system. Plant Biology, v. 15, p.369-375, 2012. Dísponivel em:< http://www.univasf.edu.br/ crad/arquivos/artigos/ Enantiostylous\%20types_Natan_Plant\%20Biology_\%202015.pdf >.doi:10.1111/j.1438 $-8677.2012 .00651 . x$

ARCEO-GOMEZ, G.; MARTINEZ, M.L.; PARRA-TABLA, V.; GARCÍA-FRANCO, J.G. Anther and stigma morphology in mirror-image flowers of Chamaecrista chamaecristoides (Fabaceae): implications for buzz pollination. Plant Biology, v.13, p.19-24, 2011. Disponível em: <http://onlinelibrary.wiley.com/doi/10.1111/j.14388677.2010.00324.x/abstract >. doi:10.1111/j.1438-8677.2010.00324.

BEGUN, A.; RAHMAN, O.; BEGUN, M. Stomatal and Trichome diversity in Senna Mill. From Bangladesh. Bangladesh Journal of Plant Taxonomy, v. 21, n. 1, p.4351, 2014. Disponível em: <http://www.banglajol.info/index.php/BJPT/article/view/192 64>. doi: 10.1590/2175-7860201566411.

BFG. Growing knowledge: an overview of Seed Plant diversity in Brazil. Rodriguésia v.66, p. 1085-1113, 2015. Disponível em:<http://www.scielo.php?pid=S217578602015000401085\&script=sci_arttext>. doi: 10.1590/2175-7860201566411.

BUSH, J.W.; URBAN, L. Insights Gained From 50 Years of Studying the Evolution of Self-Compatibility in Leavenworthia (Brassicaceae). Evolutionary Biology, v. 38, p.15-27, 2011. Disponível em: <https:/www.researchgate.net/publication/226879999 >. doi: 10.1007/s11692-010-9104-5.

CARVALHO, D.A.; OLIVEIRA, P.E.; Biologia reprodutiva e polinização de Senna sylvestris (Vell) H. S. Irwin \& Barneby (Leguminosae, Caesalpinoideae). Revista Brasileira de Botânica, v. 26, n. 3, p. 319-318, 2003. Disponível em: < http://www.scielo.br/pdf/rbb/v26n3/18951.pdf>.

COSTA, C.B.N.; LAMBERT, S.M.; BORBA, E.L.; QUEIROZ, L.P. Post-zygotic Reproductive Isolation Between Sympatric Taxa in the Chamaecrista desvauxii Complex (Leguminosae-Caesalpinioideae). Annals of Botany p.1-11, 2007. Disponível em: <https://researchgate.net/publication/6474638>. doi: 10.1093/aob/mc m012.

DAFNI, A.; KEVAN, P.G.; HUSBAND, B.C. Practical pollination biology. Cambridge: Enviroquest, 590 p, 2005.

FERREIRA, Q.I.X. \& ARAUJO, F.P. Economia de pólen favorecida pela heteranteria em Desmocelis villosa (Melastomataceae). Rodriguésia, v. 67, n. 2, p.347-355, 2016. Disponível em: <http://www.scielo.br/scielophp?pid=S2175-786020160002003 47\&script=sci>. doi: $10.1590 / 2175-7860201667206$.

FERRER, M.M.; CEN, E.M.B.; ROBERTO, M. E.C.; TEC, L.A.C.; MARTÍNEZ, C.A. H.; KAN, A. E.M.; UC, Y.J.M.; UICAB,L.R.S.;CANCHÉ, M.G.T. Las diferentes formas de las flores: pistilos cambiantes, o de cómo volar entre espejos o ser una especie flexible. Bioagrociencia, v. 4, n. 1, 2011. Disponível em: < http://www.ccba.uady.mx/revistas/bioagro/V4N1/Articulo2.pdf>. 
FERRER, M.M. \& GOOD, S.V. Self-sterility in flowering plants: preventing selffertilization increases family diversification rates. Annals of Botany, v. 110 n. 3, p. 535-553, 2012. Disponível em: < http://aob.oxfordjournals.org/content/early/2012/06/ 08/aob.mcs124.full.pdf+html>. doi: 10.1093/aob/mcs124.

GANDOLPHI, G. \& BITTENCOURT JÚNIOR, N.S. Sistema reprodutivo do IpêBranco - Tabebuia roseo- alba. (Ridley) Sandwith. Acta Botanica Brasilica, p. 840851. 2010. Disponível em: < http://www.scielo.br/scielo.php?script=sci_arttex\&pid=S0 1012- 33062010000300026>. doi: 10.1590/S0102-33062010000300026

GOTTSBERGER, G.; GOTTSBERGER, I. S. Evolution of flower strictures and pollination in neotropical Cassinae (Caesalpiniaceae) species, Physton (Austria), v. 28, n. 2, p. 293-320, 1988. Disponível em: < http://www.zobodat.at/pdf/PHY_28_2_02 93-0320.pdf>.

GUIMARAES, L. E; CHAVES FILHO, J. T; SILVA-NETO, C. M; OLIVEIRO, F. D. Estresse hídrico na germinação e desenvolvimento inicial de Handroanthus avellanedae (Lorentz ex Griseb.) Mattos em ambiente protegido. Enciclopédia Biosfera, v. 11, p. 997-1005, 2015. Disponível em: < http://www.conhecer.org.br/enciclop/2015b/agrarias/estresse\%20hidrico\%20na\%20g erminacao.pdf>.

IRWIN H.S e BARNEBY R.C. The American Cassinae: a synoptical revision of Leguminosae tribe Cassieae subtribe Cassiinae in the New World. Memoirs of the New York Botanical Garden, v. 35, p. 636- 895, 1982. Disponível em: < http://mertzdigital.nybg.org/cdm/ref/collection/p9016coll16/id/4841>.

LAPORTA, C. Floral Biology and reproductive system of enantiostylous Senna corymbosa (Caesalpiniaceae). Revista de Biologia Tropical, v. 53, p. 49-61, 2005. Disponível em: < http://www.scielo.sa.cr/scielo.php?script=sci_arttext\&pid=S003477442005000100006>.

MARAZZI, B.; CONTI, E.; ENDRESS P.K. Diversity in anthers and stigmas in the buzz pollinated genus Senna (Leguminosae, Cassinae).International Journal of Plant Sciences., v. 168, n. 4, p. 371-391, 2007. Disponível em: www.systbot.uzh.ch/static/.../marazzi_senna_IJPS_2007.pdf>.

MESQUITA-NETO, J. N.; SILVA-NETO, C. M.; FRANCESCHINELLI, E.V. heoretical predictions of plant-pollinator interactions in sympatric species of Psychotria (Rubiaceae) in Cerrado of Brazil. Plant Ecology and Evolution, v. 148, n. 2, p. 229-236, 2015. Disponível em: <https://www.researchgate.net/

publication280495149_Theoretical_predictions_of_plantpollinator_interactions_in_sy mpatric_species_of_Psychotria_Rubiaceae_in_Cerrado_of_Brazil >.doi:10.5091/plec evo.2015.983

PAPADOPULOS, A.S.T; BAKER, W.J; CRAYN, D; BUTLIN, R.K; KYNAST, R.J; HUTTON, I; SAVALAINEN, V. Speciation with gene flow on Lord Howe Island. 
Proceedings of the National Academy of Sciences of the United States, v.108 n. 32, p. 13188-13193, 2011. Disponível em: <http://www.pnas.org/content/108/32/131 88abstract>. doi: 10.1073/pnas.1106085108.

SOARES-NETO, J.P.; BEZERRA, A.R.G.; MOSCON, E.S. Probabilidade e análise decadal da precipitação pluvial da cidade de Barreiras Bahia, Brasil. Revista Brasileira de Geografia Física, v. 06, n. 03, p. 470-477, 2013. Disponível em: <http://www.revista.ufpe.br/rbgfe/index.php/revista/article/viewArticle/560>

RADUSKI, A.R.; HANEY, E.B.; IGIC, B. The expression of self-incompatibility in angiosperms is bimodal. Evolution, v. 66, n. 4, p. 1275-1283, 2011. Disponível em: $<\quad$ http://onlinelibrary. wiley.com/doi/10.1111/j.1558-5646.2011.01505.x/full>. doi: 10.1111/j.1558-5646.2011.01505.x.

RECH, A. R.; AGOSTINI, K.; OLIVEIRA, P.E.; MACHADO, I.C. Biologia da polinização. Rio de Janeiro: Projeto cultural, 527p. 2014.

RICHARDS, A.J. Plant breeding systems. London : Chapman \& Hall, 529p, 1997.

SILVA NETO, C. M.; LIMA, F.G.; Gonçalves, B.B; BERGAMINI, L.L.; BERGAMINI, B.A. R; ELIAS , M.A.S. ; FRANCESCHINELLI,E.V. Native bees pollinate tomato flowers and increase fruit production. Journal of Pollination Ecology, v. 11, n. 6, p.41-45, 2013. Disponível em: <http://www.pollinationecology.org/index.php?journal= \&page $=$ article\&op $=$ view\&path\%5B\%5D=251\&path\%5B\%5D=71>.

SILVA, C.G.; MARINHO, M.G.V.; LUCENA, M.F.A.; COSTA, J.G.M. Levantamento etnobotânico de plantas medicinais em área de Caatinga na comunidade do Sítio Nazaré, município de Milagres, Ceará, Brasil. Revista Brasileira de Plantas Medicinais, Campinas, v.17, n.1, p.133-142, 2015. Disponível em: < http://www.sciel o.br/pdf/rbpm/v17n1/1983-084X-rbpm-17-01-00133.pdf>.

MAIA-SILVA, C.; SILVA, C.I.; HRNCIR, M.; QUEIROZ, R.T.; IMPERATRIZFONSECA, V.L. Guia de Plantas visitadas por abelhas na Caatinga. 1. Ed., Fortaleza, CE: Editora Fundação Brasil Cidadão, 2012.

SOUZA, I. M.; COUTINHO, K.; FUNCH, L.S. Estratégias fenológicas de Senna cana (Nees \& Mart.) H.S.Irwin \& Barneby (Fabaceae: Caesalpinioideae) como mecanismo eficiente para atração de polinizadores, Ver. Acta Botânica Brasilica, v. 26, n. 2, p.435-443, 2012. Disponível em: < http://www.scielo.br/scielo. php?script=sci_arttext ext\&pid=S0102-33062012000200019 > . doi: 10.1590/S0102-33062012000200019.

TAKEUTI, K.L; RAIMUNDO, D.L, BANDARRA, P.M; OLIVEIRA, L.G.S; BOABAID, F.M; BARRETO, L; DRIEMEIER, D. Outbreak of poisoning by Senna ocidentais in Grazzing cattle. Acta Scientiae Veterinariae, v. 39, 2011. Disponível em: <http://www.ufrgs.br/actavet/39-1/PUB\%20954.pdf>.

WOLOWSKI, M; FREITAS, L. Sistema reprodutivo e polinização de Senna multijuga (Fabaceae) em Mata Atlântica Montana. Revista Rodriguesia, v. 61, n. 2, p.167179. 2010. Disponível em: < http://rodriguesia.jbrj.gov.br/FASCICULOS/rodrig61_2/2030-09.pdf>. 